
D:\Nsurg \Vol. 24, No. 3, Jul. - Sep., 2020\Nsurg-10.Doc
Fig. 1 Color
(A)
P. $296-300$
II

\title{
Surgical Outcome of Open Carpal Tunnel Release Using Global Symptom Severity Score (GSS)
}

\author{
MUHAMMAD NAWAZ KHAN ${ }^{1}$, RIAZ-UR-REHMAN ${ }^{2}$, RIZWAN ULLAH KHATTAK ${ }^{1}$ \\ ATTIYA NASIR SIDDIQUE' ${ }^{\mathbf{1}}$ M. ALI NOMAN ${ }^{\mathbf{1}}$ \\ Department of Neurosurgery, 'Hayatabad Medical Complex \\ ${ }^{2}$ Lady Reading Hospital, Peshawar - Pakistan
}

Doi: $10.36552 /$ pjns.v24i3.472

\begin{abstract}
Objective: Purpose of conducting this study was to evaluate the surgical outcome of open carpal tunnel release using Global Symptom Severity score (GSS) in our local setting.

Material and Methods: This prospective analytical study was conducted in the Neurosurgery Department Hayatabad Medical Complex, Peshawar. We operated consecutive 105 Carpal tunnel syndrome cases over a period of 2 years via open carpal tunnel release (OCTR) method. All of these cases were surgically indicated. All patients were evaluated preoperatively with clinical assessment and NCS. Cases were operated under local anesthesia as a day case surgery. Patients were evaluated at 3 months follow-up visit using global symptom severity score (GSS) and compared with pre operative GSS. The paired sample test was applied to obtain p value.
\end{abstract}

Results: Total 105 patients were operated during study period. 72 (69\%) patients were women and 33 (31\%) were men. The mean age of patients was 41 years. 70 (66.66\%) procedures were done for the right hand and 35 (33.33\%) were performed for left hand. Pre-op Mean GSS score was $27 \pm 2.5$ which decreased to $2.1 \pm 0.43$ postoperatively $(P<0.005)$.

Conclusion: Carpal tunnel syndrome is more commonly affecting the dominant hand of middle aged females. Open carpal tunnel release procedure is the safe and effective treatment for this compressive neuropathy.

Keywords: Global Symptom Severity score (GSS), Carpal tunnel syndrome, carpal tunnel syndrome, Carpal tunnel release.

Abbreviations: GSS: Global Symptom Severity score. OCTR: Open Carpal Tunnel Release. CTS: Carpal Tunnel Syndrome. OCTR: Open Carpal Tunnel Release.

\section{INTRODUCTION}

Carpel tunnel syndrome is common prevailing peripheral nerve compression, which is caused by thickened carpal ligament compressing the median nerve. Patients usually present with pain, paraesthesia and hypoesthesia in the median nerve dermatome. Excluding palm of hand, which is usually not affected. ${ }^{1}$

The transverse carpal ligament covers the carpal tunnel in the wrist and palm. It is thickest in its distal part. Here the carpal tunnel is the narrowest as well. ${ }^{2}$
Increased pressure inside the tunnel in any form like tissue expansion, tendon or synovial inflammation cause disruption of the microcirculation in the area. This impairment of vascular supply causes the altered potential inside the median nerve, progressive demyelination and axonal loss. ${ }^{3}$ According to some studies the prevalence of CTS is approximately $3 \%{ }^{4}$ It is more common in obese patients. ${ }^{5}$ Carpel tunnel syndrome poses a burden on health and social costs. ${ }^{6}$

Carpal tunnel syndrome can be managed as, conservative or operative. The conservative method 
includes the use of wrist splint, avoid over use of wrist, NSAIDS, and steroid injection. ${ }^{7}$ There is a high rate of recurrence with steroid injection. ${ }^{8}$ Initially, the patients are treated conservatively. Surgery is offered to those not responding to conservative management or if the patient develops progressive motor deficit. There are mainly two types of surgical procedures, open surgery and endoscopic. Open surgery is considered to be the definitive treatment option.

In our set up we perform open surgery (OCTR). This procedure is done after giving local anesthesia and it involves a linear incision. The ligament is cut carefully to relieve compression of the median nerve. ${ }^{9}$ Endoscopic (ECTR) surgery is performed either through a two or a single port technique. ${ }^{10}$ It allows the smaller cosmetically acceptable scar with lesser tissue damage. The advantage is a bit earlier recovery and return to work as compared to OCTR. However the clinical outcome is not much different. ${ }^{11}$

Recurrence after carpal tunnel release surgery is uncommon. It may be more common after ECTR. ${ }^{12}$ Various causes of CTS recurrence may be, A: Misdiagnosis; pain and paresthesias may be due some other reasons, B: Surgical Error; residual ligament left behind, C: Delayed procedure; surgery is done when the irreversible axonal loss has already occurred, D: Surgical Complications; infection, compressive scar, nerve injury, hematoma.

The complication and failure rate according to some studies has been estimated from $0 \%$ to $19 \%$ after one year of follow-up. Among them, $12 \%$ were requiring surgery after OCTR. ${ }^{13}$

The outcome of CTR has been assessed using different methods and scoring systems in literature. In our study, we have used the global symptom severity score (GSS). Purpose of conducting this study was to evaluate the surgical outcome of open carpal tunnel release using Global Symptom Severity score (GSS) in our local setting.

\section{MATERIAL AND METHODS}

\section{Study Design \& Setting}

This was the Prospective analytical study. This study was conducted at Neurosurgery Department Hayatabad Medical Complex, Peshawar from July $1^{\text {st }}$ 2017 to July $31^{\text {st }} 2019$.

\section{Sampling}

We operated consecutive 105 Carpal tunnel syndrome cases over a period of 2 years via open carpal tunnel release (OCTR) method only those patients included in study sample which were diagnosed in the study setting within the study duration hence non probability convenient sampling technique applied.

\section{Inclusion Criteria}

Patients of all ages and gender were included in the study.

\section{Exclusion Criteria}

Patients having carpal tunnel syndrome previously operated were excluded from the study.

\section{Surgical Technique}

All cases were operated under local anesthesia as a day case surgery. Baseline investigations were done to assess the general health of the patients. A $2-2.5 \mathrm{~cm}$ incision given medial to the thenar crease just opposite to the third web space. It extended proximally not beyond the distal wrist crease and not more than Kaplan's line at the midpalmar area. After making skin incision and dissection in subcutaneous fat transverse carpal ligament identified under surgical loupe and sectioned layer by layer to its full thickness. Wound washed with normal saline and sutured in layers. Sutures were removed after two weeks of surgery.

\section{Data Collection}

Patients were evaluated at 3 months follow up visit using global symptom severity score (GSS) and compared with pre operative GSS. The GSS is a clinical scoring system in which CTS symptom severity is graded by patient from 1 to 10 for 5 symptoms, i.e., 1) pain, 2) numbness, 3) paraesthesia, 4) weakness and 5) nocturnal pain. The total score is calculated by adding scores of all 5 symptoms hence total GSS score ranges from $5-50$. Patients were evaluated at 3 months follow-up visit using global symptom severity score (GSS) and compared with pre operative GSS.

\section{Data Analysis}

The paired sample test was applied to obtain $\mathrm{p}$ value by comparing pretest and post test mean values sat confidence interval 95\% using SPSS 22. 


\section{RESULTS}

\section{Gender Distribution}

Total 105 patients were operated during the study period. $72(69 \%)$ patients were women and $33(31 \%)$ were men (Table 1).

Table 1: Gender Distribution.

\begin{tabular}{|l|c|c|c|}
\hline Sex & Number & Percentage & Cumulative Percentage \\
\hline Female & 72 & $69 \%$ & $69 \%$ \\
\hline Male & 33 & $31 \%$ & $31 \%$ \\
\hline Total & 105 & $100 \%$ & $100 \%$ \\
\hline
\end{tabular}

\section{Age Range}

The mean age of cases was $41 \pm 28.5$ (Table 2).

Table 2: Age Stratification.

\begin{tabular}{|c|c|c|}
\hline Age (Years) & Frequency & Percentage \\
\hline $20-29$ & 15 & $14.28 \%$ \\
\hline $30-39$ & 16 & $15.23 \%$ \\
\hline $40-49$ & 39 & $37.14 \%$ \\
\hline $50-59$ & 19 & $18.09 \%$ \\
\hline$>60$ & 16 & $15.19 \%$ \\
\hline
\end{tabular}

\section{Clinical Presentation}

$70(66.66 \%)$ procedures were done for the right hand and $35(33.33 \%)$ were for left hand (Table 3$)$.

Table 3: Side Involved.

\begin{tabular}{|l|c|c|c|}
\hline Side & Number & Percentage & Cumulative Percentage \\
\hline Right & 70 & $66.66 \%$ & $66.66 \%$ \\
\hline Left & 35 & $33.33 \%$ & $33.3 \%$ \\
\hline Total & 105 & $100 \%$ & $100 \%$ \\
\hline
\end{tabular}

It is evident that females are most commonly effected gender than males 2.2: 1 . The most common age group affected was $40-49$ years 39 (37.14\%) cases. The dominant hand is most commonly affected. Patient with bilateral CTS had more severe symptoms on their dominant side.

\section{Outcome}

Seventy five $(71.42 \%)$ patients were asymptomatic 4 weeks after the surgery while $25(23.80 \%)$ patients had some symptoms beyond 4 weeks out of which 20 were symptom free at 8 weeks after surgery three patients re-operated and two patients lost follow-up. Pre op mean GSS score was $27 \pm 2.5$ which decreased to 2.1 \pm 0.43 postoperatively ( $p$ value: 0.002 ) i.e., there was a significant average difference between pre-op and post op mean GSS and the scores are moderately weak but positively correlated.

Table 4: Post-operative Outcome of 4 Weeks and 8 Weeks.

\begin{tabular}{|l|c|c|c|c|c|}
\hline Outcome & Asymptomatic & Moderate Symptoms & Severe Symptoms & Redo-Surgery & Lost to Follow-up \\
\hline 4 Weeks & 75 & 25 & 5 & Nil & Nil \\
\hline 8 Weeks & 90 & Mild 10 & 3 & 03 & 02 \\
\hline 3 Months & $100(95-20 \%)$ & & & & \\
\hline
\end{tabular}

Table 5: GSS: Global Symptoms Severity Score.

\begin{tabular}{|l|c|c|c|}
\hline Gender & $\begin{array}{c}\text { Pre-operative } \\
\text { GCS }\end{array}$ & $\begin{array}{c}\text { Post-operative } \\
\text { GCS }\end{array}$ & P-value \\
\hline Female & $27 \pm 25$ & $2.1 \pm 0.43$ & 0.002 \\
\hline Male & 25 & $2.4 \pm 0.43$ & $31 \%$ \\
\hline Mean & 25.7 & 1.7 & $100 \%$ \\
\hline
\end{tabular}




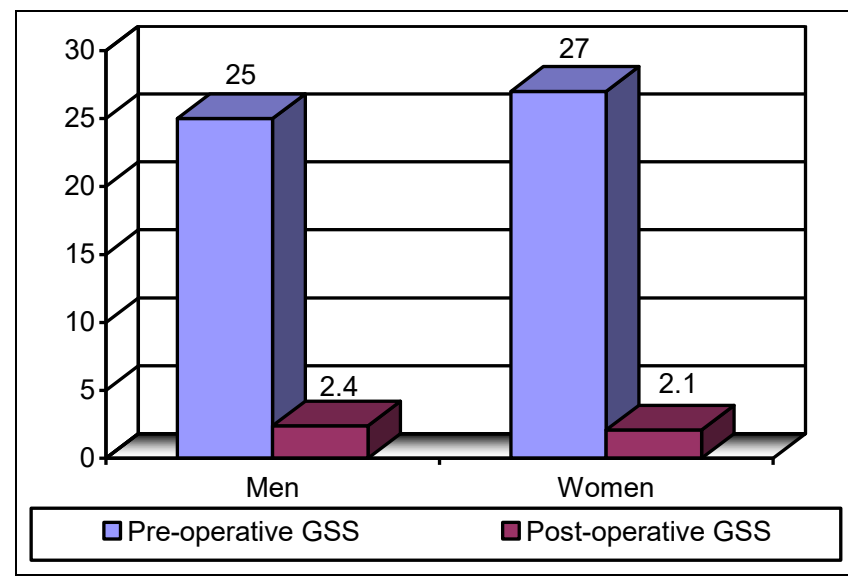

Fig. 2: Gender Stratification of Mean GSS Score (Preoperative \& Post-operative).

\section{DISCUSSION}

Carpal tunnel syndrome is mainly clinical diagnosis. Most of the clinicians are able to diagnose this condition readily. ${ }^{14}$ The validity of clinical tests in terms of diagnosis is under debate. Kushner et al found the validity of Phalen test and Tinel sign as having a sensitivity of $60 \%$ and $49 \%$ and specificities of $80 \%$ and 55\% respectively. ${ }^{15}$ Nerve conduction studies are usually done for confirmation before going for surgery. We operated all our cases after considering both clinical tests as well as the NCS. In our study, CTS was more common in middle aged females (female/male ratio 2.2: 1) in the dominant right hand (66.66\% in right hand vs. $33.33 \%$ ). 100 out of 105 $(95.23 \%)$ patients were symptoms free at $3^{\text {rd }}$ monthly follow-up, three patients failed to resolve sign symptoms after even six months post op, these patients were re operated. There was distal residual band in 2 cases and a residual proximal band in one case. Pre op mean GSS score was $27 \pm 2.5$ which decreased to 2.1 \pm 0.43 post-operative at $3^{\text {rd }}$ monthly follow up hence, GSS decreased by average 25 points which is a significant success of the procedure. There was no injury to the median nerve or the palmar cutaneous branch or named vessel even in a single case in the entire series, but 6 cases had a superficial surgical site infection which resolved conservatively. Turner A et al published good to excellent long term outcome in $70 \%-90 \%$ of the cases following open Carpal tunnel release surgery. ${ }^{16}$ Isik HS et al operated 143 CTR cases. Their results were similar to ours. They didn't report any single neurovascular intra op complication. The mean global symptom severity score (GSS) was 25.7 pre-operative and 1.7 post-operative. ${ }^{17}$ The majority of the women in our study were housewives and those working in fields, taking care of cattle. The majority of affected males were laborers, mechanics, electricians, plumbers and office workers.

\section{Limitations}

Although our study gives a fair picture of the outcome of the open CTR procedure in our setup and local population but it has limitations. We couldn't follow patients for long term outcome and complications. Moreover other modes of treatment of CTS i.e., steroid injections length of conservative trial/ duration of disease could not be studied which could affect the outcome or could have given further stratification of data to suggest treatment strategies. All of the cases were operated by surgeons of different surgical experience and seniority level results could not be stratified according to the experience level of operating surgeons. Moreover, it is a single neurosurgery unit study of which cannot be generalized unless the multicentric study is conducted.

\section{CONCLUSION}

Carpal tunnel syndrome is a frequently prevalent condition in working age groups more commonly affecting the dominant hand of middle aged females. Open carpal tunnel release surgery is the safe and effective treatment for this compressive neuropathy.

\section{REFERENCES}

1. Brain WR, Wright AD, Wilkinson M. Spontaneous compression of median nerve in carpal tunnel. Lancet. 1947; 1: 277.

2. Fowler JR, Munsch M, Huang Y, Hagberg WC, Imbriglia JE. Preoperative electrodiagnostic testing predicts time to resolution of symptoms after carpal tunnel release. J Hand Surg Eur. 2016; 41 (2): 137-42.

3. Bland JDP. Carpal tunnel syndrome. Clinical review. BMJ. 2007; 335: 343-6.

4. Atroshi I, Gummesson C, Johnsson R, et al. Prevalence of carpal tunnel syndrome in a general population. JAMA. 1999; 282: 153-8.

5. Lam N, Thurston A. Association of obesity, gender, age and occupation with carpal tunnel syndrome. Aust N Z J Surg. 1998; 68: 190-3.

6. Wildin C, Dias J, Heras-Palou C, et al. Trends in elective hand surgery referrals from primary care. The Royal College of Surgeons of England. 2006; 88 (6): 543-46. 
7. Practice parameter for carpal tunnel syndrome (summary statement). Report of the Quality Standards Subcommittee of the American Academy of Neurology. Neurology. 1993; 43: 2406-9.

8. Marshall S, Tardif G, Ashworth N. Local corticosteroid injection for carpal tunnel syndrome. Cochrane Database Syst Rev. 2007; (2): CD001554.

9. Taleisnik J. The palmer cutaneous branch of the median nerve and the approach to the carpal tunnel. An anatomical study. J. Bone Joint Surg. 1973; 55A: 1212 17.

10. Chow JCY. The Chow technique of endoscopic release of the carpal ligament for carpal tunnel syndrome. Four years of clinical results. Arthroscopy, 1993; 9: 301-14.

11. Thoma A, Veltri K, Haines T. A meta-analysis of randomised controlled trials comparing endoscopic and open carpal tunnel decompression. Plast Reconstructr Surg. 2004; 114: 1137-1146.
12. Concannon MJ, Brownfield ML, Puckett CL. The incidence of recurrence after endoscopic carpal tunnel release. Plast Reconstr Surg. 2000; 105: 1662-5.

13. Botte MJ, von Schroeder HP, Abrams RA, Gellman H. Recurrent carpal tunnel syndrome. Hand Clin. 1996; 12: 731-43.

14. Phalen GS. The carpal tunnel syndrome: Clinical evaluation of 598 hands. Clin Orthop. 1972; 8: 29-40.

15. Kuschner SH, Ebramzadeh E, Ohnson D, Brien WW, Sherman R. Tinel's sign and Phalen's test in carpal tunnel syndrome. Orthopaedics. 1992; 15: 1297-302.

16. Turner A, Kimble F, Gulyas K, Ball J. Can the outcome of open carpal tunnel release be predicted? A review of the literature. ANZ J Surg. 2010; 80: 50-4.

17. Isik HS, Bostanci U. Experience of Carpal Tunnel Syndromethat operated using a limited uni skin incision. Turk Neurosurg. 2011; 21: 177-80.

\section{Additional Information}

Disclosures: Authors report no conflict of interest.

Ethical Review Board Approval: The study was conformed to the ethical review board requirements.

Human Subjects: Consent was obtained by all patients/participants in this study.

Conflicts of Interest:

In compliance with the ICMJE uniform disclosure form, all authors declare the following:

Financial Relationships: All authors have declared that they have no financial relationships at present or within the previous three years with any organizations that might have an interest in the submitted work.

Other Relationships: All authors have declared that there are no other relationships or activities that could appear to have influenced the submitted work.

Date of Submission: 11-05-2020

Date of Revision: 20-8-2020

Date of Online Publishing: 25-09-2020

Date of Print: 30-09-2020
Address for Correspondence: Riaz-ur-Rehman

Assistant Prof. Neurosurgery, Department of MTI

Lady Reading Hospital, Peshawar

Email:drriazurrehman@yahoo.com

\section{AUTHORS CONTRIBUTIONS}

\begin{tabular}{|l|l|l|}
\hline Sr.\# & Author's Full Name & Intellectual Contribution to Paper in Terms of: \\
\hline 1. & M. Nawaz Khan & Study design and methodology. \\
\hline 2. & Riaz-ur-Rehman & Paper writing, referencing, data calculations and \\
\hline 3. & Rizwan Ullah Khattak & Literature review and manuscript writing \\
\hline 4. & Attiya Nasir & Data collection and calculations \\
\hline 5. & M. Ali Noman & Analysis of data and interpretation of results etc. \\
\hline 6. & Shahid Ayub & Analysis of data and quality insurer \\
\hline
\end{tabular}

